\title{
Mandatory communication skills training for oncologists: enforcement does not substantially impact satisfaction
}

\author{
Céline Bourquin • Friedrich Stiefel • Jürg Bernhard • \\ Gabriella Bianchi Micheli • Liselotte Dietrich • \\ Christoph Hürny • Brigitta Wössmer • Alexander Kiss
}

Received: 10 January 2014 / Accepted: 31 March 2014 / Published online: 12 April 2014

(C) Springer-Verlag Berlin Heidelberg 2014

\begin{abstract}
Purpose Even though there is evidence that both patients and oncology clinicians are affected by the quality of communication and that communication skills can be effectively trained, so-called Communication Skills Trainings (CSTs) remain heterogeneously implemented.

Methods A systematic evaluation of the level of satisfaction of oncologists with the Swiss CST before (2000-2005) and after (2006-2012) it became mandatory.

Results Levels of satisfaction with the CST were high, and satisfaction of physicians participating on a voluntary or mandatory basis did not significantly differ for the majority of the items.

Conclusions The evaluation of physicians' satisfaction over the years and after introduction of mandatory training supports
\end{abstract}

All authors (except CB) are members of the National Task Force for Communication Skills Training in Oncology of the Swiss Cancer League.

C. Bourquin $\cdot$ F. Stiefel $(\bowtie)$

Psychiatric Liaison Service, Lausanne University Hospital, Bugnon

44, 1011 Lausanne, Switzerland

e-mail: frederic.stiefel@chuv.ch

J. Bernhard

Department of Medical Oncology, Bern University Hospital, Bern,

Switzerland

G. Bianchi Micheli

Service of Psychiatry and Medical Psychology, Lugano, Switzerland

L. Dietrich

Herisau, Switzerland

C. Hürny

Geriatric Clinic, St. Gallen, Switzerland

B. Wössmer · A. Kiss

Psychosomatic Division, Department of Internal Medicine, Basel

University Hospital, Basel, Switzerland recommendations for generalized implementation of CST and mandatory training for medical oncologists.

Keywords Communication Skills Training · Medical oncologists $\cdot$ Satisfaction $\cdot$ Mandatory training

\section{Introduction}

The efficacy of Communication Skills Training (CST) in improving communication skills of oncology clinicians has been repeatedly demonstrated by randomized controlled trials [1-4] and confirmed by systematic reviews and meta-analyses [5-10]. CST leads to more patient-centered communicationcharacterized, for example, by increases in empathic responses to patient cues and time devoted to psychosocial issues during consultations - it reduces clinicians' professional stress and burnout [11,12], and acquired skills are often enduringly translated into clinical practice [1,13-15]. As highlighted in the systematic review of Uitterhoeve et al. and in the 2013 Cochrane review on CST, the effectiveness of CST on patient outcomes has only recently become of interest to researchers, and no definite evidence was found for such effectiveness $[8,10]$.

The main purpose of CST is to support clinicians when structuring the medical interview, exchanging information, responding to emotion, building the relationship with the patient, and adapting to his/her cognitive, emotional, and relational needs.

Despite this background, there is an important heterogeneity with regard to implementation of CST in oncology.

In Switzerland, CST was introduced in 2000 and has been declared mandatory for physicians specializing in medical oncology since 2006 [16]. Physicians' satisfaction with 
training on a voluntary basis compared with mandatory training is of relevance since participants who are not satisfied indicate that they do not consider to have benefited from training.

Some specific objectives of CST, such as an improved perception of patients' relational needs and an increased adaptation to their defensive style, request from participants an active engagement and a willingness to reflect on own fears and defensive styles emerging in the encounter with the patient. If clinicians are obliged and show dissatisfaction to participate in CST, such objectives may be endangered: to evaluate satisfaction with CST is therefore an important issue when recommending mandatory training.

Determining whether mandatory training decreases participants' satisfaction, thus possibly hampering the outcome of CST, is therefore important. If participants report decreased satisfaction, the decision of the Swiss Society of Medical Oncology to render CST mandatory would have to be revisited. However, if participants remain predominantly satisfied, one might argue that CST should also be implemented on a mandatory basis in other countries, which would be in line with a recent state-of-the-art review stressing that "CST programs ought now to be part of oncology fellowship training offered by comprehensive cancer centers" [17].

\section{Materials and methods}

\section{The Swiss model of CST}

The Swiss CST for oncology clinicians (physicians and nurses) initiated in 1998 by the Swiss Cancer League and implemented — after being piloted — in 2000, became mandatory after 2005 for physicians specializing in medical oncology $[16,18]$.

The training consists of a 2-day course for up to 12 oncology clinicians that is based on interactive case discussions of critical incident reports delivered by the participants, roleplays, and video feedback of participants' interviews with simulated patients, and is followed by four to six individual supervisions and a final half-day training course 6 months later. To use the time most effectively, video feedback is provided in two separate subgroups. The CST addresses four interdependent aspects of communication: structure of the consultation, exchange of information, empathic response to emotions, and relationship building. Supervision takes place in the trainer's office (French- and Italian-speaking parts of Switzerland) or is provided over the phone (German-speaking part of Switzerland). During supervision, participants present videotapes of their consultations or discuss sensitive issues they encounter.

Mandatory training, interdisciplinary participation, and individual supervision are distinctive features of the Swiss model of CST [18]. All Swiss trainers have attended a trainthe-trainer course and have extensive experience in psychooncology, supervision of oncology clinicians, or psychotherapy. Their professional backgrounds include psychiatry, psychology, and psychosomatic medicine, with one trainer being a nurse with training and experience in supervision. Since its implementation, 610 oncology clinicians, comprising 321 physicians and 289 nurses, have participated in the Swiss CST.

\section{Satisfaction of participants}

The Swiss CST is evaluated by the participants right after the 2-day course (course evaluation) and after termination of the follow-up training (evaluation of the supervisions and halfday training). The evaluation is based on questionnaires rating participants' level of satisfaction with key elements of the training (see Table 1). Items are rated on a six-point Likert scale from not satisfied at all (1) to very satisfied (6).

\section{Results}

Table 1 illustrates that physicians were very satisfied with the CST course, with means of all 12 items ranging from 5 to 6 (very satisfied) before and after CST became mandatory.

Most importantly, satisfaction of physicians participating voluntarily in the CST and those whose participation was mandatory did not significantly differ for the majority of the items $(P>.05)$, indicating a stable mean level of satisfaction over the 13-year period. However, significant changes were observed for the following items: conceptualization of the content (item 1), level of information (item 2), work in small groups (item 7), involvement during the course (item 10), and organization (item 12). Although these changes indicate a decreased level of satisfaction after training became mandatory, mean level of satisfaction remained high and differences were rather small. Decreases were in the range of $5 \%$ and thus are unlikely to reflect a substantial impact on satisfaction.

Levels of satisfaction with the follow-up training were also high, between 5 and 6 for all the means, and were significantly stable ( $P>.05$ for all compared means (six items) before and after CST became mandatory).

\section{Discussion}

Despite the self-confronting experience, cost, and invested time, participants reported a high level of satisfaction with the Swiss CST before and after it became mandatory. This result is in line with our observation that even physicians who indicate ambivalent feelings at the beginning of training (e.g., "I am here because I have to participate" or "It's needed to be 
Table 1 Physicians' evaluation of the Swiss CST (2000-2012)

\begin{tabular}{|c|c|c|c|c|c|c|c|}
\hline \multirow{2}{*}{$\begin{array}{l}\text { Items } \\
\text { Level of satisfaction with }\end{array}$} & \multicolumn{3}{|c|}{ Pre-mandatory (2000-2005) } & \multicolumn{3}{|c|}{ Post-mandatory (2006-2012) } & \multirow[t]{2}{*}{$P$ value } \\
\hline & Mean & SD & Range (min-max) & Mean & SD & Range (min-max) & \\
\hline \multicolumn{8}{|l|}{ Course } \\
\hline Number of respondents: & \multicolumn{3}{|c|}{$\mathrm{N}=150$} & \multicolumn{3}{|c|}{$\mathrm{N}=164$} & \\
\hline $\begin{array}{l}\text { 1. Conceptualization of the content } \\
\text { [discussed topics] }\end{array}$ & 5.50 & 0.63 & $3-6$ & 5.32 & 0.72 & $2-6$ & .020 \\
\hline $\begin{array}{l}\text { 2. Level of information } \\
\text { [theory] }\end{array}$ & 5.37 & 0.61 & $3-6$ & 5.10 & 0.81 & $2-6$ & .001 \\
\hline $\begin{array}{l}\text { 3. Didactic tools } \\
\text { [technical support, handouts, and critical } \\
\text { incident reports for case discussion] }\end{array}$ & 5.42 & 0.66 & $4-6$ & 5.27 & 0.84 & $2-6$ & .090 \\
\hline $\begin{array}{l}\text { 4. Practical relevance } \\
\text { [usefulness for clinical practice] }\end{array}$ & 5.65 & 0.60 & $3-6$ & 5.56 & 0.65 & $3-6$ & .214 \\
\hline $\begin{array}{l}\text { 5. Presentation of information } \\
\text { [way of teaching patient-centered communication] }\end{array}$ & 5.18 & 0.71 & $2-6$ & 5.04 & 0.84 & $2-6$ & .119 \\
\hline 6. Trainers & 5.48 & 0.97 & $2-6$ & 5.61 & 0.63 & $3-6$ & .164 \\
\hline $\begin{array}{l}\text { 7. Work in small groups } \\
\text { [video feedback with subgroups of participants] }\end{array}$ & 5.79 & 0.44 & $4-6$ & 5.56 & 0.68 & $2-6$ & .001 \\
\hline $\begin{array}{l}\text { 8. Atmosphere during the course } \\
\text { [safety of the setting] }\end{array}$ & 5.61 & 0.61 & $3-6$ & 5.64 & 0.59 & $4-6$ & .619 \\
\hline $\begin{array}{l}\text { 9. Opportunities to take an active part } \\
\text { [interactivity between participants, disciplines, } \\
\text { and trainers] }\end{array}$ & 5.78 & 0.45 & $4-6$ & 5.73 & 0.52 & $3-6$ & .382 \\
\hline $\begin{array}{l}\text { 10. Involvement during the course } \\
\text { [own participation] }\end{array}$ & 5.69 & 0.52 & $4-6$ & 5.40 & 0.69 & $2-6$ & .000 \\
\hline $\begin{array}{l}\text { 11. Usefulness for own individual } \\
\text { professional activity } \\
\text { [transfer of skills into clinical practice] }\end{array}$ & 5.21 & 0.73 & $3-6$ & 5.32 & 0.73 & $3-6$ & .173 \\
\hline $\begin{array}{l}\text { 12. Organization } \\
\text { [practical aspects related to course organization] }\end{array}$ & 5.57 & 0.64 & $3-6$ & 5.08 & 0.91 & $2-6$ & .000 \\
\hline \multicolumn{8}{|l|}{ Follow-up } \\
\hline Number of respondents: & \multicolumn{3}{|c|}{$\mathrm{N}=96$} & \multicolumn{3}{|c|}{$\mathrm{N}=155$} & \\
\hline $\begin{array}{l}\text { 1. Practical proceedings (phone calls, group) } \\
\text { [practical aspects related to supervisions and } \\
\text { half-day training] }\end{array}$ & 5.58 & 0.59 & $4-6$ & 5.48 & 0.63 & $3-6$ & .186 \\
\hline $\begin{array}{l}\text { 2. Didactic proceedings (GAS, video, etc.) } \\
\text { [Gain Attainment Scales (GAS), video] }\end{array}$ & 5.44 & 0.61 & $4-6$ & 5.41 & 0.68 & $1-6$ & .677 \\
\hline $\begin{array}{l}\text { 3. Learning achievements } \\
\text { [benefits of the CST] }\end{array}$ & 5.13 & 0.70 & $2-6$ & 5.22 & 0.68 & $3-6$ & .285 \\
\hline $\begin{array}{l}\text { 4. Usefulness for own individual } \\
\text { professional activity } \\
\text { [transfer of skills into clinical practice] }\end{array}$ & 5.45 & 0.69 & $2-6$ & 5.42 & 0.80 & $1-6$ & .774 \\
\hline $\begin{array}{l}\text { 5. Work in small groups } \\
\text { [video feedback during half-day course] }\end{array}$ & 5.46 & 0.68 & $3-6$ & 5.38 & 0.67 & $3-6$ & .372 \\
\hline 6. Trainers & 5.86 & 0.32 & $5-6$ & 5.80 & 0.43 & $4-6$ & .214 \\
\hline
\end{tabular}

Results of the nurses' evaluation are not presented because the CST is not mandatory for nurses; however, nurses' satisfaction levels did not differ overall from those of the physicians

licensed as an oncologist") most often actively engage in the training and change from passive resistance to motivated participation [18].

CST not only aims to teach an interview technique (how to structure the interview, to provide complex information, etc.) but also to confront physicians with their own communication behavior and psychological functioning. More specifically, CST allows participants to increase their awareness of their communication and defensive style and to identify the nature of their emotions during interviews with patients and their way to handle them [19], which implies openness to the training. The fact that the level of satisfaction of physicians does not decrease when the Swiss CST became mandatory may indicate that these objectives continue to be reached despite the obligation to be trained and the participation of physicians who would not attend such training on their own 
initiative. From another perspective, the results may also reflect increasing expertise in teaching of CST and psychotherapeutic competence of the trainers.

The evaluation of physicians' level of satisfaction over the years and after introduction of mandatory training supports recommendations for generalized implementation of CST and mandatory training for oncologists, as formulated in a position paper based on a consensus meeting among European experts [20].

The introduction of mandatory CST for oncologists in other countries would be a powerful message to the medical community, to patients, and to society as a whole, indicating that physician-patient communication matters in cancer care.

Conflict of interest The authors have no financial relationship with the organization that sponsored the research and have no conflict of interest to disclose. The authors have full control of all primary data and agree to allow the journal to review their data if requested.

\section{References}

1. Fallowfield L, Jenkins V, Farewell V et al (2002) Efficacy of a cancer research UK communication skills training model for oncologists: a randomised controlled trial. Lancet 359:650-656

2. Delvaux N, Merckaert I, Marchal S et al (2005) Physicians' communication with a cancer patient and a relative: a randomized study assessing the efficacy of consolidation workshops. Cancer 13:23972411

3. Wilkinson S, Perry R, Blanchard K, Linsell L (2008) Effectiveness of a three-day communication skills course in changing nurses' communication skills with cancer/palliative care patients: a randomized controlled trial. Palliat Med 22:365-375

4. Liénard A, Merckaert I, Libert Y et al (2010) Is it possible to improve residents breaking bad news skills? A randomised study assessing the efficacy of a communication skills training program. Br J Cancer 103:171-177

5. Cegala DJ, Lenzmeier Broz S (2002) Physicians communication skills training: a review of theoretical backgrounds, objectives and skills. Med Educ 36:1004-1016

6. Gysels M, Richardson A, Higginson IJ (2004) Communication training for health professionals who care for patients with cancer: a systematic review of effectiveness. Support Care Cancer 12:692-700
7. Rao JK, Anderson LA, Inui TS, Frankel RM (2007) Communications interventions make a difference in conversations between physicians and patients: a systematic review of the evidence. Med Care 45:340-349

8. Uitterhoeve RJ, Bensing JM, Grol RP et al (2010) The effect of communication skills training on patient outcomes in cancer care: a systematic review of the literature. Eur J Cancer Care 19:442-457

9. Barth J, Lannen P (2011) Efficacy of communication skills training courses in oncology: a systematic review and meta-analysis. Ann Oncol 22:1030-1040

10. Moore PM, Rivera Mercado S, Grez Artigues M, Lawrie TA (2013) Communication skills training for healthcare professionals working with people who have cancer (Review). Cochrane Database Syst Rev 3:CD003751

11. Delvaux N, Razavi D, Marchal S et al (2004) Effects of a 105 hours psychological training program on attitudes, communication skills and occupational stress in oncology: a randomized study. Br J Cancer 90:106-114

12. Libert Y, Merckaert I, Reynaert C et al (2007) Physicians are different when they learn communication skills: influence of the locus of control. Psychooncology 16:553-562

13. Fallowfield L, Jenkins V, Farewell V, Solis-Trapala I (2003) Enduring impact of communication skills training results of a 12-month followup. Br J Cancer 89:1445-1449

14. Razavi D, Merckaert I, Marchal S et al (2003) How to optimize physicians' communication skills in cancer care: results of a randomized study assessing the usefulness of posttraining consolidation workshops. J Clin Oncol 21:3141-3149

15. Finset A, Ekeberg O, Eide H, Aspegren K (2003) Long term benefits of communication skills training for cancer doctors. Psychooncology 12:686-693

16. Kiss A (1999) Communication skills training in oncology: a position paper. Ann Oncol 10:899-901

17. Kissane DW, Bylund CL, Banerjee SC et al (2012) Communication skills training for oncology professionals. J Clin Oncol 30:12421247

18. Stiefel F, Bernhard J, Bianchi G et al (2011) The Swiss model. In: Kissane DW, Bultz BD, Butow PN, Finlay I (eds) Handbook of communication in oncology and palliative care. Oxford University, Oxford, pp 641-648

19. Bernard M, de Roten Y, Despland JN, Stiefel F (2010) Communication Skills Training and clinicians' defenses in oncology: an exploratory study. Psychooncology 19:209-215

20. Stiefel F, Barth J, Bensing J et al (2010) Communication skills training in oncology: a position paper based on a consensus meeting among European experts in 2009. Ann Oncol 21:204-207 